\title{
KUALITAS PAPAN KOMPOSIT LIMBAH KULIT BATANG SAGU (Metroxylon sp) DAN PLASTIK POLIPROPILENA BERDASARKAN JUMLAH LAPISAN PENYUSUN
}

\author{
(Quality of Composite Board from Sago Stem Bark Wastes (Metroxylon sp) and Polypropylene \\ Plastic Based on Number of Composite Layers)
}

\author{
Mayang Archila, Farah Diba, Dina Setyawati, Nurhaida \\ Fakultas Kehutanan Universitas Tanjungpura. Jalan Imam Bonjol Pontianak 78124 \\ email : mayang.archila@gmail.com
}

\begin{abstract}
The objective of this research is to evaluate the effect of the number of composite layers on the quality of the composite board from sago bark waste and plastic waste, and the number of composite layers that produce the best quality on composite board. The composite board is made with size $30 \mathrm{~cm} \times 30 \mathrm{~cm} \times 1 \mathrm{~cm}$. The composition and division of the material was carried out manually with the polypropylene distribution divided into three parts: the front and rear respectively of $15 \%$, and the center $70 \%$ of the plastic weight. Target density of composite boards was $0.7 \mathrm{~g} / \mathrm{cm}^{3}$. The treatment used is based on the number of layers composing, which is 5 layers, 7 layers, 9 layers, 11 layers and 13 layers. After mixed the sago bark particle and waste of polypropylene, the materials then compressed with hot press at $180^{\circ} \mathrm{C}$ with pressure about $\pm 25 \mathrm{~kg} / \mathrm{cm}^{2}$ for 10 minutes. The composite boards then tested the quality included physical and mechanical properties. Testing of physical and mechanical properties refers to JIS A 5908-2003 standard. Physical properties consist of density, moisture content, thickness swelling, and water absorption. Mechanical properties consist of modulus of rupture, modulus of elasticity, internal bonding, and modulus of screw holding strength. The study used a completely randomized design experiment consisting of 5 treatments and 3 replications. The results showed the average value of composite density was range between $0.6962-0.7896$ $\mathrm{g} / \mathrm{cm}^{3}$, the moisture content was range between $4.3388 \%-6.8066 \%$, the thickness swelling was range between $8.2605 \%$ - $11.9615 \%$, and water absorption was range between $17.2380 \%$ $22.3867 \%$. The average value of modulus of rupture was range between $60,0632 \mathrm{~kg} / \mathrm{cm}^{2}-$ $64,4068 \mathrm{~kg} / \mathrm{cm}^{2}$, the modulus of elasticity was range between $17935,1813 \mathrm{~g} / \mathrm{cm}^{2}-32841,8278$ $\mathrm{kg} / \mathrm{cm}^{2}$, the internal bonding was range between $1,9268 \mathrm{~kg} / \mathrm{cm}^{2}-5,4119 \mathrm{~kg} / \mathrm{cm}^{2}$, and the modulus of screw holding strength was range between $78,2530 \mathrm{~kg} / \mathrm{cm}^{2}-92,9677 \mathrm{~kg} / \mathrm{cm}^{2}$. The composite board made from sago stem bark waste and polypropylene waste plastic with 13 layers treatment is the best composite board and fulfilled the JIS A 5908-2003 standard.
\end{abstract}

Keywords: bark of sago, composite boards, layer of composite, polypropylenes plastic, waste

\section{PENDAHULUAN}

Perkembangan penduduk dari tahun ke tahun semakin meningkat. Produksi kayu sebagai bahan baku industri tahun 2012 mencapai 49,1 juta $\mathrm{m}^{3}$ per tahun, sedangkan Departemen Kehutanan memberi jatah produksi kayu secara nasional mencapai 9,1 juta $\mathrm{m}^{3}$ per tahun (Kementerian Kehutanan, 2013).
Meningkatnya kebutuhan kayu tersebut tidak diimbangi dengan kemampuan hutan dalam menghasilkan kayu, akibatnya produksi kayu semakin menipis. Upaya untuk mengatasi hal tersebut antara lain dengan membuat papan komposit, dimana bahan baku kayu diganti dengan bahan lignoselulosa lain untuk bahan baku dalam pembuatan papan komposit. 
Menurut Badan Litbang Kehutanan (2007) luas areal sagu semi budidaya di Kalimantan sebesar 20.000 hektar. Kulit batang sagu merupakan salah satu limbah yang belum termanfaatkan dengan baik. Selama ini, kulit batang sagu hanya digunakan untuk kayu bakar. Di sisi lain, kulit batang sagu mengandung selulosa $(56,86 \%)$ dan lignin yang lebih banyak $(37,70 \%)$ daripada ampas sagu sehingga kulit batang sagu dan ampas sagu juga dapat digunakan sebagai pengisi dalam pembuatan papan partikel (Kiat, 2006). Di lain pihak, limbah plastik di Indonesia meningkat setiap tahunnya. Salah satu penyebabnya adalah pertumbuhan penduduk yang tinggi. Plastik merupakan sampah anorganik yang sulit terurai, sehingga perlu waktu puluhan tahun untuk menguraikan komponen dari plastik serta memberikan dampak negatif terhadap lingkungan. Menurut Kementerian Lingkungan Hidup dan Kehutanan (2015) produksi sampah meningkat 175.000 ton per hari atau 64 juta ton/tahun. Sekarang ini, pengelolaan plastik melalui konsep daur ulang belum dinilai maksimal sehingga perlu pengendalian yang efektif dan efesien dalam penanganan limbah plastik agar mendatangkan manfaat bagi masyarakat. Plastik merupakan salah satu bahan perekat yang termasuk dalam perekat thermosetting. Polipropilena merupakan salah satu jenis termoplastik yang umum digunakan sebagai bahan perekat papan komposit. Menurut Setyawati, et al (2006) plastik polipropilena dapat digunakan sebagai bahan perekat dalam pembuatan papan komposit yang memiliki stabilitas yang tinggi akan tetapi memiliki sifat mekanik yang rendah.

Papan komposit merupakan istilah umum untuk panel yang dibuat dari partikel kayu atau bahan berlignoselulosa lainnya yang diikat dengan perekat dengan kempa panas pada tekanan tertentu (Pease, 1994). Saat ini, komposit tidak hanya terbatas pada produk panel, tetapi meliputi produk lainnya seperti molding, kayu gergajian, komponen, dan produk yang yang dibuat dengan mengkombinasikan kayu atau limbah pertanian dengan material lain, misalnya plastik atau jerami (Maloney, 1996).

Seiring dengan tuntutan seperti isu lingkungan, kelangkaan kayu, tuntutan konsumen, pengetahuan dan penguasaan ilmu, serta berbagai faktor lain yang merangsang terciptanya produk komposit yang berkualitas tinggi, berbagai macam bahan non kayu dimungkinkan sebagai bahan baku papan komposit (Rowell, 1998). Indonesia sebagai negara agraris menghasilkan sekitar 1 juta ton sabut kelapa (FAO, 1999), 39,5 juta ton ampas tebu, dan limbah sagu mencapai 24 hingga 39 juta ton per tahun (Adam, 2010).

Walaupun dari studi literatur yang dilakukan diketahui telah banyak penelitian pembuatan papan komposit dengan menggunakan limbah pertanian (Pearce dan Sellers, 2000; Subiyanto et al, 2003, Monteiro et al, 2005, Hakim dan Febrianto, 2006) namun sampai saat ini belum ada pabrik papan komposit di Indonesia yang menggunakan bahan baku dari limbah tersebut. Selain masih tingginya masalah pencemaran lingkungan oleh limbah yang dihasilkan dari kegiatan 
pemanenan maupun pengolahan tanaman tersebut (Syakir et al, 2008; Setyawati et al, 2006) dan kualitas papan yang dihasilkan, terutama sifat kekuatan maupun stabilitas dimensinya, masih belum memenuhi standar yang ditetapkan. Selain itu kebanyakan penelitian tersebut menggunakan perekat termoseting yang mengandung senyawa formaldehida.

Penelitian mengenai komposit kayu plastik/lignoselulosa sudah banyak dilaporkan (Han dan Shiraishi, 1990; Kazayawako dan Balatinecz, 1997; Johnson et al, 1997; Febrianto et al, 2006) namun masih berfokus pada extruded material, dimana serbuk kayu digunakan sebagai bahan pengisi atau penguat pada matriks termoplastik (Wolcott, 2003). Oleh sebab itu aplikasinya masih sulit diterapkan oleh industri di Indonesia karena memerlukan investasi yang sangat tinggi. Disamping itu, produk yang dihasilkan belum berupa produk panel seperti papan komposit komersial yang kita kenal, tetapi berupa lembaran tipis $(0,3) \mathrm{mm}$. Plastik yang digunakan juga bukan berasal dari limbah tetapi dari plastik murni, sehingga kontribusinya terhadap penanganan limbah plastik masih terbatas.

Limbah plastik merupakan masalah bagi lingkungan karena sifat yang dimiliki plastik, seperti tidak dapat membusuk, tidak terurai secara alami, tidak dapat menyerap air, serta tidak dapat berkarat. Salah satu alternatif yang dapat ditempuh untuk mengatasi masalah tersebut adalah dengan proses daur ulang. Setyawati et al (2008) menyatakan bahwa salah satu cara pemanfaatan plastik daur ulang adalah sebagai bahan baku pembuatan komposit kayu plastik. Jenis termoplastik yang dapat digunakan untuk tujuan tersebut antara lain adalah plastik polipropilena (PP) dan polietilena (PE) karena memiliki titik leleh yang lebih rendah dari suhu yang menyebabkan kayu mulai terdekomposisi $\left(<200^{\circ} \mathrm{C}\right)$.

Sampai saat ini, berdasarkan studi literatur yang ada, penelitian penggunaan plastik, terlebih dalam bentuk limbah, sebagai perekat pada produk komposit seperti papan partikel maupun papan serat masih sangat jarang dilakukan (Wolcott, 2003). Penelitian sebelumnya yang dilakukan Xu et al (1998), Setyawati dan Massijaya, (2005) menyatakan bahwa produk papan komposit dengan perekat termoplastik memiliki berbagai keuntungan dibandingkan komposit umumnya yang menggunakan perekat konvensional/ termoseting seperti urea formaldehida, melamin formaldehida, dan fenol formaldehida, terutama dalam hal kestabilan dimensi dan emisi formaldehida. Akan tetapi masih banyak aspek yang perlu diteliti dalam pengembangannya agar dapat dikembangkan di industri.

Pada penelitian ini akan dilakukan serangkaian penelitian mengenai perlakuan bahan baku dan faktor-faktor kunci pembuatan komposit yang paling tepat untuk menghasilkan papan komposit yang berkualitas dan ramah lingkungan. Faktor- faktor yang berperan penting dalam pembuatan komposit dengan bahan plastik adalah tipe dan bentuk bahan baku, jenis kayu/bahan lignoselulosa, rasio kayu dengan matriks, aditif, serta kondisi pada saat pengadonan (Han dan Shiraishi, 
1990; Stark dan Berger, 1997, Febrianto et al, 2006).

Menurut Setyawati et al (2008) perlakuan perendaman panas selama 2 jam pada serat sagu, menghasilkan papan komposit dengan sifat mekanik yang lebih tinggi dibandingkan papan komposit tanpa perlakuan perendaman serat. Selanjutnya dari hasil penelitian pendahuluan, diketahui bahwa jumlah lapisan penyusun dalam proses pembuatan papan komposit berpengaruh terhadap kualitas papan yang dihasilkan. Namun belum diketahui jumlah lapisan yang menghasilkan kualitas papan terbaik. Oleh karena itu tujuan dari penelitian adalah mengetahui pengaruh dari jumlah lapisan penyusun terhadap kualitas papan komposit dari limbah kulit batang sagu dan limbah plastik dan untuk mengetahui pengaruh dari jumlah lapisan penyusun yang menghasilkan papan komposit terbaik yang memenuhi standar JIS A 5908-2003.

\section{METODE PENELITIAN}

Penelitian dilaksanakan di Laboratorium Pengolahan Kayu Fakultas Kehutanan dan Laboratorium Teknologi Kayu Fakultas Kehutanan, sebagai tempat persiapan bahan baku dan PT. Duta Pertiwi Nusantara (DPN) sebagai tempat untuk pembuatan papan komposit dan pengujian sifat fisik dan mekanik. Waktu penelitian selama \pm 4 bulan, mulai bulan Agustus 2016 - November 2016.

Bahan yang digunakan pada penelitian ini adalah serat dari limbah kulit batang sagu dan limbah plastik polipropilena. Serat sagu diperoleh dari limbah kulit batang sagu yang didapat di daerah Desa Tebang Kacang Kabupaten Kubu Raya. Limbah batang sagu dibersihkan dari sisa pati yang menempel. Kemudian dipukul agar menjadi sabut atau serat, lalu dibersihkan agar bebas dari pati sagu. Serat tersebut dipotong dengan panjang $\pm 30 \mathrm{~cm}$, kemudian dilakukan perendaman panas selama 2 jam dengan suhu air $\pm 80^{\circ} \mathrm{C}$. Serat kulit sagu ditiriskan dan dikeringanginkan selama \pm 1 minggu hingga mencapai kadar air kering udara yaitu $\pm 12 \%$. Selanjutnya serat dikeringkan dalam oven pada suhu $60{ }^{0} \mathrm{C} \pm 2{ }^{0} \mathrm{C}$ hingga mencapai kadar air $\pm 5 \%$. Kemudian plastik polipropilena dibersihkan, dijemur dan dipotong dengan ukuran kecil $\pm 1 \mathrm{~cm}$ yang di peroleh dari pengolahan sampah Jl. Trans Kalimantan, Kabupaten Kubu Raya.

Papan komposit dibuat dengan ukuran $30 \mathrm{~cm}$ x $30 \mathrm{~cm}$ x $1 \mathrm{~cm}$ dengan target kerapatan $0,7 \mathrm{~g} / \mathrm{cm}^{3}$ dengan rasio serat plastik 50:50. Komposisi dan pembagian bahan dilakukan secara manual dengan distribusi polipropilena dibagi menjadi tiga bagian yaitu bagian muka dan belakang masing-masing sebanyak $15 \%$, dan bagian tengah $70 \%$ dari berat plastik (Setyawati et al, 2008). Perlakuan yang digunakan adalah perlakuan berdasarkan jumlah lapisan penyusun, yaitu 5 lapis, 7 lapis, 9 lapis, 11 lapis dan 13 lapis. Pengempaan panas dilakukan pada suhu $180^{\circ} \mathrm{C}$ dan tekanan $\pm 25 \mathrm{~kg} / \mathrm{cm}^{2}$ selama 10 menit (Setyawati et al, 2006). Kemudian dilakukan pengkondisian contoh uji selama 7 hari dengan suhu ruangan agar kadar air seragam dan menghilangkan stress pada papan komposit tersebut. Pengujian sifat fisik dan mekanik mengacu pada standar JIS A 5908-2003, sifat fisik (kerapatan, kadar air, pengembangan tebal, daya serap air), dan 
sifat mekanik (keteguhan lentur, keteguhan patah, keteguhan rekat, kuat pegang sekrup). Penelitian menggunakan percobaan Rancangan Acak Lengkap (RAL) yang terdiri dari 5 perlakuan dan 3 kali ulangan.

HASIL DAN PEMBAHASAN
Nilai kerapatan papan komposit dari limbah kulit batang sagu dan plastik polipropilene pada berbagai jumlah lapisan berkisar antara $0,6962 \mathrm{~g} / \mathrm{cm}^{3}-$ $0,7896 \mathrm{~g} / \mathrm{cm}^{3}$. Nilai rata-rata kerapatan papan komposit dapat dilihat pada Gambar 1 .

\section{Kerapatan}

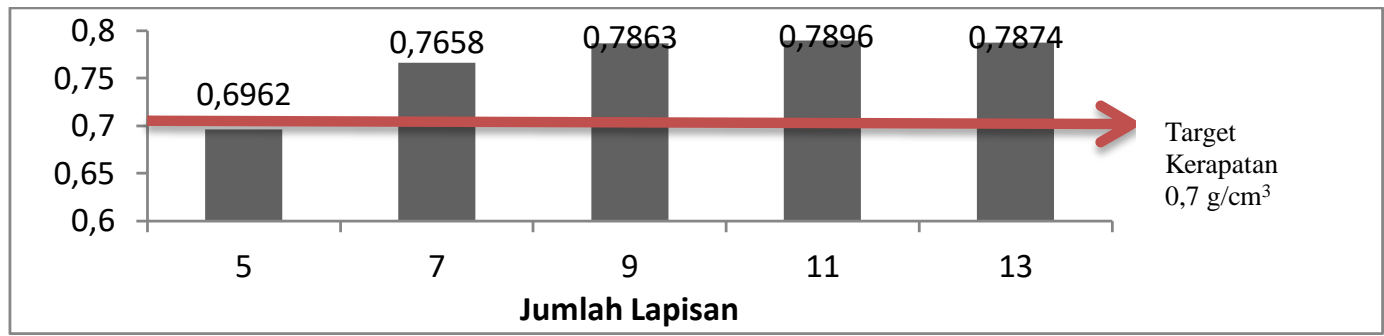

Gambar 1. Nilai kerapatan papan komposit dari kulit batang sagu dan limbah plastik polipropilena pada berbagai jumlah lapisan (density value of composite boards made from waste of sago bark and waste of polypropylene plastic with different number of layer)

Hasil kerapatan papan komposit pada penelitian ini secara umum menghasilkan nilai yang lebih tinggi dari target kerapatan sasaran yaitu $0,7 \mathrm{~g} / \mathrm{cm}^{3}$. Hal ini diduga spilasi yang digunakan terlalu tinggi sehingga menambah berat papan komposit yang dihasilkan. Berdasarkan analisis sidik ragam jumlah lapisan berpengaruh nyata terhadap peningkatan nilai kerapatan papan komposit. Hal ini disebabkan karena komposisi plastik tidak merata di setiap lapisan pada saat pembentukan lembaran, walaupun sudah diusahakan serata mungkin. Proses pembuatan papan komposit dengan banyaknya jumlah lapisan penyusun ini bertujuan untuk membuat komposisi plastik lebih merata disetiap lapisannya. Semua nilai kerapatan papan komposit telah memenuhi standar JIS A 5908-2003.

\section{Kadar Air}

Nilai kadar air papan komposit dari limbah kulit batang sagu dan plastik polipropilene pada berbagai jumlah lapisan berkisar antara 2,7299\% 4,6931\%. Nilai rata-rata kadar air papan komposit disajikan pada Gambar 2. 


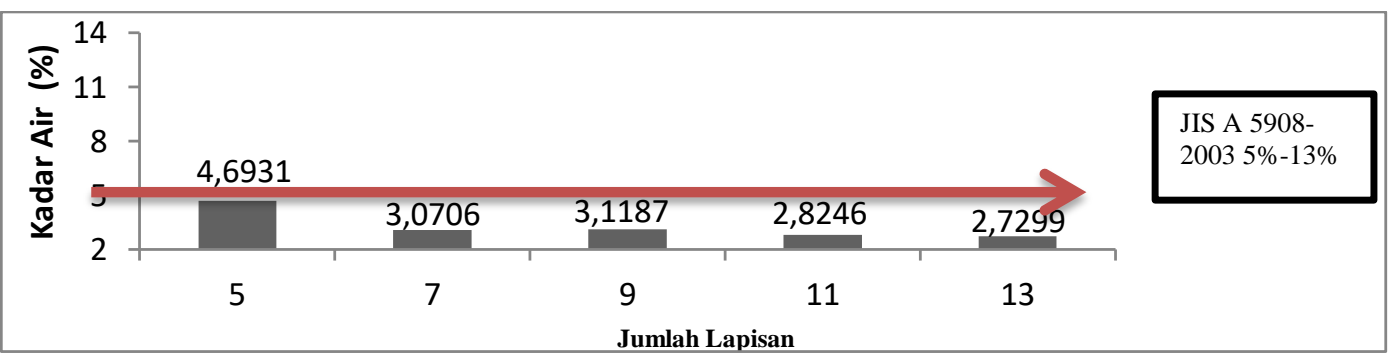

Gambar 2. Nilai kadar air papan komposit dari kulit batang sagu dan limbah plastik polipropilena pada berbagai jumlah lapisan (moisture content value of composite boards made from waste of sago bark and waste of polypropylene plastic with different number of layer)

Semua nilai kadar air papan komposit belum memenuhi standar JIS A 59082003 yang mensyaratkan nilai kadar air sebesar 5-13\%. Hasil kadar air papan komposit secara umum menghasilkan nilai yang semakin rendah dengan bertambahnya jumlah lapisan. Semakin banyak jumlah lapisan yang digunakan, maka kadar air papan komposit yang dihasilkan semakin kecil. Hal tersebut disebabkan makin banyak jumlah lapisan, penyebaran plastik yang digunakan sebagai perekat akan makin seragam, sehingga akan berpengaruh terhadap kerapatan dan kemampuan papan menyerap air. Plastik yang digunakan sebagai perekat bersifat hidrofobik (menahan air), sehingga papan komposit tidak mudah menyerap uap air dari lingkungan.

3. Pengembangan Tebal

Nilai pengembangan tebal papan komposit limbah kulit batang sagu dari limbah kulit batang sagu dan plastik polipropilene pada berbagai jumlah lapisan berkisar antara 8,2605\% $11,9615 \%$. Nilai rata-rata pengembangan tebal papan komposit disajikan pada Gambar 3.

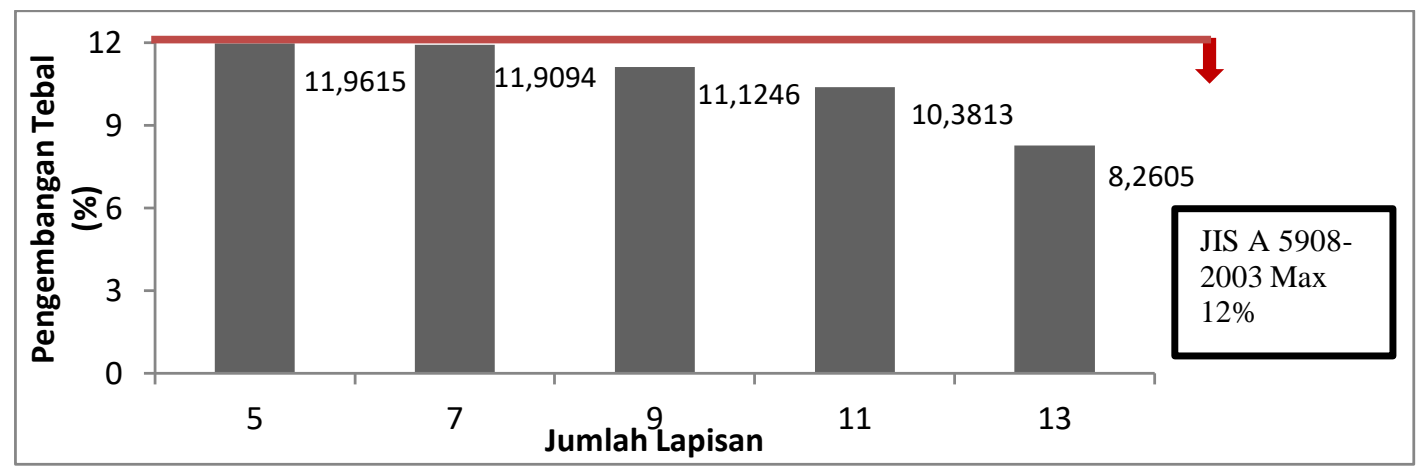

Gambar 3. Nilai pengembangan tebal papan komposit dari kulit batang sagu dan limbah plastik polipropilena pada berbagai jumlah lapisan (thickness swelling value of composite boards made from waste of sago bark and waste of polypropylene plastic with different number of layer)

Nilai rata-rata pengembangan tebal papan komposit dari limbah batang sagu dan limbah plastik polipropilena pada berbagai lapisan telah memenuhi standar 
JIS A 5908-2003 yang mensyaratkan nilai maksimal $12 \%$. Semakin banyak jumlah lapisan maka pengembangan tebal papan komposit yang dihasilkan semakin kecil. Semakin banyaknya jumlah lapisan maka penyebaran plastik lebih merata, sehingga perekatan menjadi lebih sempurna. Hal ini menyebabkan penyerapan air lebih sedikit.

\section{Daya Serap Air}

Nilai daya serap air papan komposit dari limbah kulit batang sagu berkisar antara $17,2380 \%-22,3867 \%$. Nilai ratarata daya serap air disajikan pada Gambar 4.

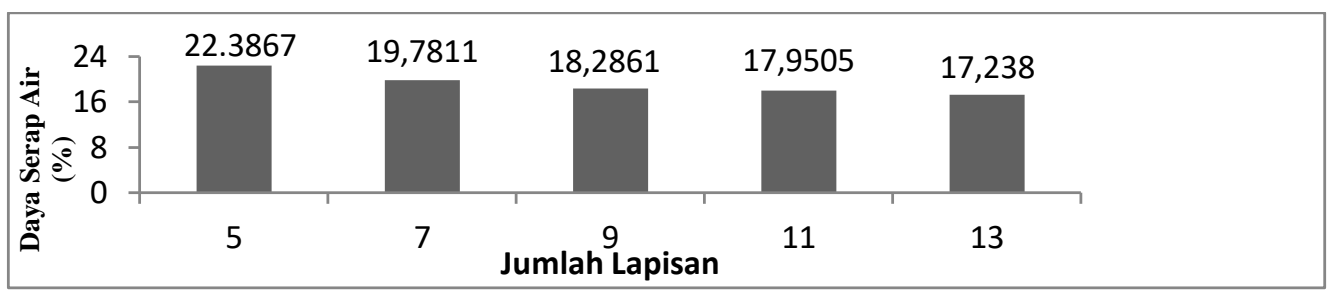

Gambar 4. Nilai daya serap air papan komposit dari kulit batang sagu dan limbah plastik polipropilena pada berbagai jumlah lapisan (water absorption value of composite boards made from waste of sago bark and waste of polypropylene plastic with different number of layer)

Daya serap air papan komposit dari kulit batang sagu dan limbah plastik polipropilena pada berbagai jumlah lapisan menunjukkan dengan banyaknya jumlah lapisan memiliki daya serap air yang lebih rendah. Hal ini disebabkan karena banyaknya jumlah lapisan, maka penyebaran plastik lebih merata.Pada papan komposit dengan jumlah lapisan penyusun yang sedikit menyebabkan sebagian serat tidak tertutup oleh perekat dengan sempurna, sehingga papan komposit mudah menyerap air. Standar JIS A 59082003 tidak mensyaratkan nilai daya serap air, akan tetapi uji daya serap air dapat digunakan untuk menentukan aplikasi penggunaan papan komposit untuk pemakaian eksterior atau interior.

5. Keteguhan Lentur (Modulus of Elasticity, MOE)

Nilai rata-rata keteguhan lentur papan komposit dari limbah kulit batang sagu dan limbah plastik polipropilena pada berbagai jumlah lapisan berkisar antara $17935,1813 \mathrm{~kg} / \mathrm{cm}^{2}-32841,8278$ $\mathrm{kg} / \mathrm{cm}^{2}$. Nilai rata-rata keteguhan lentur disajikan pada Gambar 5. 


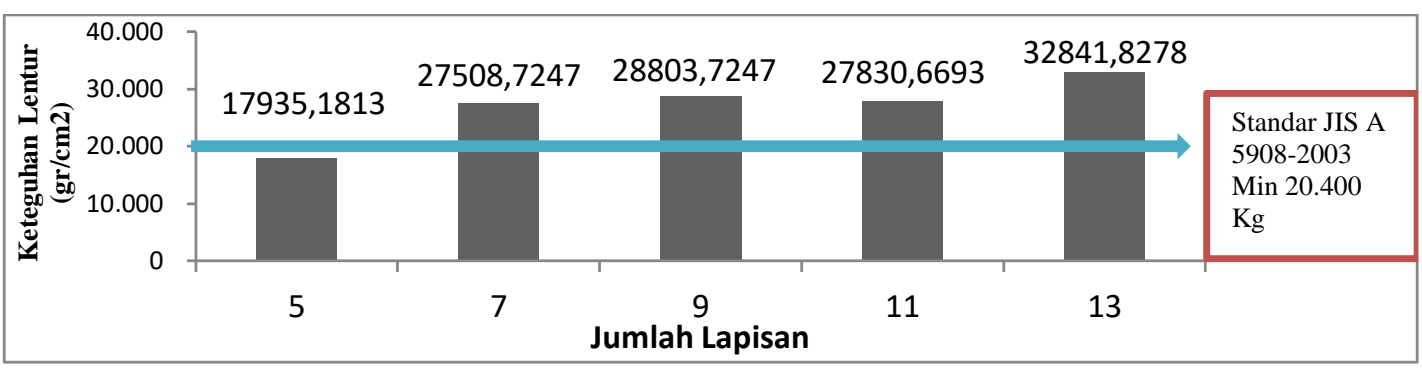

Gambar 5. Nilai keteguhan lentur papan komposit dari kulit batang sagu dan limbah plastik polipropilena pada berbagai jumlah lapisan (modulus of elasticity value of composite boards made from waste of sago bark and waste of polypropylene plastic with different number of layer)

Nilai keteguhan lentur papan komposit dari kulit batang sagu dan limbah plastik polipropilena pada jumlah lapisan 7 sampai 13 telah memenuhi standar JIS A 59082003 yang mensyaratkan nilai keteguhan lentur sebesar minimal $20,400 \mathrm{~kg}$. Papan komposit dengan jumlah lapisan 5 lapis yang masih belum memenuhi standar. Bertambahnya jumlah lapisan papan komposit cenderung meningkatkan nilai keteguhan lentur. Hal ini disebabkan karena keteguhan lentur berhubungan dengan kekuatan papan. Semakin besar ketahanannya terhadap perubahan bentuk, semakin tinggi keteguhan lentur papan.Berdasarkan hasil analisis keragaman dengan makin banyaknya jumlah lapisan penyusun, penyebaran plastik yang digunakan sebagai perekat papan komposit menjadi lebih merata, sehingga kualitas perekatan papan komposit yang dihasilkan juga makin meningkat.

6. Keteguhan Patah ( Modulus of Rupture, MOR)

Nilai rata-rata keteguhan patah papan komposit dari limbah kulit batang sagu dan limbah plastik polipropilena pada berbagai jumlah lapisan berkisar antara $60,0623 \mathrm{~kg} / \mathrm{cm}^{2}-64,4068$ $\mathrm{kg} / \mathrm{cm}^{2}$. Nilai rata-rata keteguhan patah papan komposit disajikan pada Gambar 6.

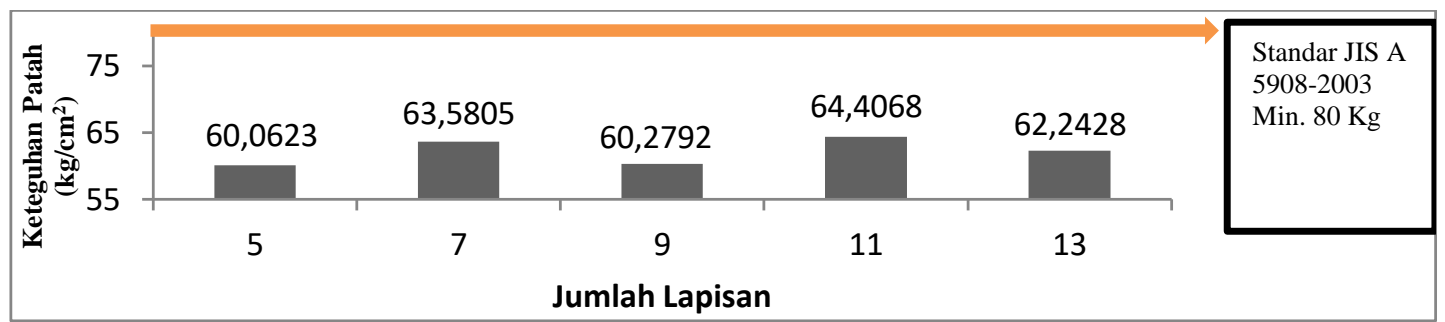

Gambar 6. Nilai keteguhan patah papan komposit dari kulit batang sagu dan limbah plastik polipropilena pada berbagai jumlah lapisan (modulus of rupture value of composite boards made from waste of sago bark and waste of polypropylene plastic with different number of layer) 
Nilai keteguhan patah papan komposit seragam dengan bertambahnya jumlah lapisan penyusun. Hal ini diduga karena serat sagu yang mudah patah apabila diberikan beban dikarenakan hilangnya komponen zat yang ada didalam kulit sagu akibat dari perendaman panas. Meningkatnya jumlah lapisan penyusun juga menyebabkan nilai keteguhan rendah. Dikarenakan meratanya perekat di tiap lapisan menyebabkan plastik bersifat kaku sehingga ketika diberi beban plastik mudah lentur. Hal ini menyebabkan keteguhan patah yang didapat tidak memenuhi standar JIS A 5908-2003. Berdasarkan hasil analisis keragaman untuk keteguhan patah papan komposit ternyata jumlah lapisan penyusun tidak memberikan pengaruh nyata terhadap keteguhan lentur papan komposit.

\section{KESIMPULAN}

1. Jumlah lapisan pada pembuatan papan komposit dari limbah kulit batang sagu dan limbah plastik poli propilena berpengaruh terhadap sifat fisik dan mekanik papan komposit yang dihasilkan.

2. Papan komposit dari limbah kulit batang sagu dan limbah plastik poli propilena dengan perlakuan 13 lapis menghasilkan papan komposit yang terbaik yang memenuhi standar JIS A 59082003.

\section{DAFTAR PUSTAKA}

Adam. 2010. Pemanfaatan limbah produksi sagu sebagai pupuk kompos herbisida. Institut Teknologi Sepuluh November. Surabaya

Badan Litbang Kehutanan. 2007. Potensi Sagu, Kendala dan Prospek
Pengembangannya. Bogor : Badan Litbang Kehutanan.

Febrianto et al, 2006 Febrianto F, Setyawati D, Karina M, Bakar ES, Hadi YS. 2006. Influence of wood flour and modifier contents on the physical and mechanical properties of wood flour-recycle polypropylene composites. Journal of Biological Sciences (6)2: 337343

Food and Agricultural Organization. 1999. Improvement in drying, softening, bleaching, dyeing coir fibre/yarn and in printing coir floor coverings.

www.fao.org/documents/show_cdr .asp?url_life=/DOCREP/005/Y361 2E/y3612e03.htm (diakses 6 Maret 2006)

Han dan Shiraishi, 1990; Han G S, Shiraishi N. 1990. Composites of wood and polypropylene IV. Wood Research Sociaty at Tsubuka 36(11):976-982

Hakim dan Febrianto, 2006 Hakim L, Febrianto F. 2006. Phisical and mechanical properties of composite board made from banana fiber (Musa sp) pretreated with alkali. Proceedings of the $8^{\text {th }}$ Pasific Rim Bio-Based Composites Symposium. 20-23 November 2006. Kuala Lumpur Malaysia

JIS A 5908. 2003. Particle Board. Japanese Industrial Standard. Japanese Standards Association

Johnson et al,1997; Johnson DA, Maclean WD, Jacobson R. 1997. Agro-plastic composites: replacing polypropilene and polyethylene with wheat straw. Di dalam: Making a Business From Biomass in Energy, Environment, Chemicals, Fibers, and Materials. 
hlm 925-932

Kementerian Kehutanan. 2013. Rencana Kerja Tahun 2014 Kementerian Kehutanan Republik Indonesia. Biro Perencanaan Kementrian Kehutanan. Jakarta.

Kementerian Lingkungan Hidup dan Kehutanan. 2015. Masyarakat Indonesia Produksi Sampah 64 Juta Ton Per Tahun. http://kalteng.prokal.co/read/news/ 20429-masyarakat-indonesiaproduksi-sampah-64-juta-ton-pertahun (24 januari 2016).

Kiat LJ. 2006. Preparation and Characterization of Carboxymethyl Sago Waste and Its Hydrogel [tesis]. Malaysia : Universiti Putra Malaysia. Tidak dipublikasikan

Kazayawako dan Balatinecz, 1997; Kazayawoko M, Balatinecz JJ. 1997. Adhesion mechanisms in woodfiber-polypropylene composites. . Di dalam: Fourth International Conference on Woodfiber-Plastic Composites. Madison, 12 -14 Mei 1997. Wisconsin: Forest Product Society. hlm 81-93.

Maloney, 1996) Maloney TM.1996. The Family of composite materials. Forest Product Journal 46(2).

Monteiro et al, 2005 Monteiro SN, Terrones LAH, Lopes FPD, d'Almeida JRM. 2005. Mechanical Strenght of polyester matrix composites reinforced with coconut fiber waste. Jornal revista Materia. 10(4):571-576

Pearce dan Sellers, 2000; Pearce RJ, Sellers T. 2000. Five different agrobased particleboard bonded with urea-formaldehyde resin. Proceedings Use of Agricultural
Fibers In The Manufacture Of Composite Panels. Forest Product Society.

Pease, 1994) Pease D A, 1994. Panels : Product, Aplications and Production Trends. USA : Miller Freeman.

Rowell RM. 1998. The State of Art and Future Development of Bio-Based Composite Science and Technology Towards the 21 Century : Proceedings of The St Fourth Pasific Rim Bio-Based Composites Symposium. 2-5 November 1998. Bogor

Setyawati D dan Massijaya YM.2005. Pengembangan papan komposit berkualitas tinggi dari sabut kelapa dan plastik polipropilena daur ulang (i): suhu dan waktu kempa panas. Jurnal Teknologi hasil Hutan 18(2): 91 -101

Setyawati D, Hadi YS, Massijaya MY, dan Nugroho N. 2006. Kualitas papan komposit dari sabut kelapa dan plastik polietilena berlapis finir : variasi ukuran sabut kelapa. Jurnal Perennial 2(2):5-11

Setyawati D, YS Hadi, Y Massijaya, dan $\mathrm{N}$ Nugroho. 2008. Utilization of coir and recycled polypropylene for bamboo matting layer composite. Mol.Cryst. Liq. Cryst. Vol 484 : 23(389)-34(400)

Strak NM, Berger MJ. 1997. Effect of particle size on properties of woodflour reinforced polypropylene composites. Di dalam: Fourth International Conference on Woodfiber-Plastic Composites. Madison, 12 -14 Mei 1997. Wisconsin: Forest Product Society. hlm 134-143

Subiyanto B, Saragih R, Husin E. 2003. 
JURNAL TENGKAWANG (2017)

Vol. 7 (1) : 46 - 56

Pemanfaatan serbuk sabut kelapa sebagai bahan penyerap air dan oli berupa panel papan partikel. Jurnal Ilmu \& Teknologi Kayu Tropis 1(1):26-34

Syakir M, Bintoro MH, Agusta H, Hermanto. 2008. Pemanfaatan limbah sagu sebagai pengendalian gulmapada lada perdu. Jurnal Littri 14(3):107-112

Wolcott, MP. 2003. Formulation and process development of fullpressednwood-polyethylene composites. Forest Product Journal 53(9):25-32

Xu H, Tanaka C, Nakao T, Katayama H .1998. Mechanical properties of plywood reinforced by bamboo or jute. Forest Product Journal 48(1):81-8. 